\title{
Cefotetan Disodium
}

National Cancer Institute

\section{Source}

National Cancer Institute. Cefotetan Disodium. NCI Thesaurus. Code C47437.

The disodium salt form of cefotetan and a semi-synthetic, broad-spectrum, beta-

lactamase-resistant, second-generation cephalosporin antibiotic with bactericidal activity.

Cefotetan disodium causes inhibition of bacterial cell wall synthesis by inactivating penicillin binding proteins (PBPs) thereby interfering with the final transpeptidation step required for cross-linking of peptidoglycan units which are a component of the cell wall. This results in a reduction of cell wall stability and causes cell lysis. 